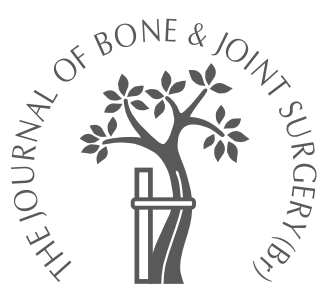

V. Guzzanti, F. Falciglia, C. L. Stanitski

From the Children's Hospital Bambino Gesù, Rome, Italy
V. Guzzanti, MD, Professor of Orthopaedic Surgery F. Falciglia, MD, Orthopaedic Surgeon Orthopaedic Department, Children's Hospital Gesù, Institute of Scientific Research, Piazza S. Onofrio 4, 00165 Rome, Italy.

C. L. Stanitski, MD, Professor of Orthopaedic Surgery

Children's Hospital of the Medical University of South Carolina, Charleston, South Carolina 29425, USA.

Correspondence should be sent to Professor V. Guzzanti.

C2004 British Editorial Society of Bone and Joint Surgery doi:10.1302/0301-620X.86B5. $14397 \$ 2.00$

$J$ Bone Joint Surg [Br] 2004;86-B:731-6.

Received 7 April 2003;

Accepted after revision

29 August 2003

\title{
Slipped capital femoral epiphysis in skeletally immature patients
}

Fixation by a single screw is considered the current treatment of choice for a slipped capital femoral epiphysis. This approach promotes premature physeal closure. The use of a modified, standard, single, cannulated screw designed to maintain epiphyseal fixation without causing premature closure of the physis was reviewed in ten patients. The nine boys and one girl aged between $\mathbf{1 0 . 6}$ and $\mathbf{1 2 . 6}$ years with unilateral slipped capital femoral epiphysis (SCFE), were markedly skeletally immature (Tanner stage I, bone age 10 to 12.6 years).

Clinical and radiological review at a mean follow-up of 44.3 months (36 to 76) showed no difference in the time to physeal closure between the involved and uninvolved side. Measurement of epiphyseal and physeal development showed continued growth and remodelling in all patients.

Use of this device provided epiphyseal stability and maintained the capacity for physeal recovery and growth following treatment for both unstable and stable slipped capital femoral epiphysis.

The aims of mechanical fixation for slipped capital femoral epiphysis (SCFE) are restoration of stability and prevention of further slipping. Avascular necrosis and chondrolysis should be avoided. The method should allow remodelling of the femoral head and neck to prevent the onset of premature degenerative joint disease. Among the many methods of treatment proposed, epiphyseal stabilisation by fixation with a single screw has become the most popular. ${ }^{1-3}$

A single screw, ${ }^{4,5}$ when correctly inserted, provides adequate epiphyseal stability and prevents the femoral physis from growing away from the fixation. ${ }^{6}$ The single screw decreases the volume occupied by metal within the epiphysis and avoids insertion into quadrants prone to cause avascular necrosis. ${ }^{7,8}$ It may also facilitate proximal femoral remodelling in mild and moderate disease. ${ }^{2,6,9,10}$ Deliberate closure of the proximal femoral physis in most cases of SCFE would not be expected to cause significant retardation of growth since the adolescents involved are near skeletal maturity. ${ }^{2,11}$ The single screw technique can present problems when used in the more skeletally immature patient. The traditional screw does not avoid proximal femoral growth problems, ${ }^{12-15}$ which can lead to functional disabilities from premature proximal physeal arrest ${ }^{11,13,14}$ and limitation of epiphyseal and metaphyseal remodelling. ${ }^{6,16-18}$

The use of a single modified screw was assessed to see if complications could be avoided in a group of patients with a unilateral SCFE who were markedly skeletally immature at the time of treatment. Metaphyseal, physeal and epiphyseal growth and remodelling were studied on radiographs and any evidence of avascular necrosis and chondrolysis noted. The clinical outcome was reviewed.

\section{Patients and Methods}

The clinical and radiological records of all patients treated for a SCFE between 1993 and 2000 were reviewed in order to identify markedly skeletally immature patients. Inclusion criteria for this study were: 1 ) unilateral mild $\left(<30^{\circ}\right)$ or moderate $\left(30^{\circ}\right.$ to $\left.\left.50^{\circ}\right) \mathrm{SCFE} ; ;^{19} 2\right)$ a predicted femoral neck growth of $>1.5 \mathrm{~mm}$ according to the patient's bone age ${ }^{20}$ pubertal level ${ }^{21}$ and expected leg growth; ${ }^{22,23} 3$ ) a complete set of radiographs available for review from treatment to proximal femoral physeal closure; and 4) follow-up of more than 36 months.

Pre-operative assessment included clinical and radiological classification of the SCFE in terms of severity (mild/moderate), type (stable/ unstable) and growth remaining. The pre- and 


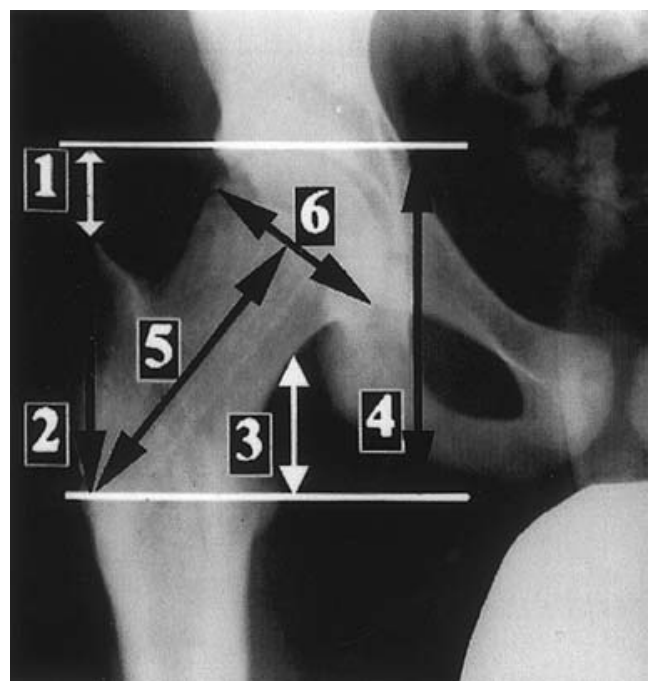

Fig. 1

Illustration of growth measurements reviewed: (1) articulotrochanteric distance; (2) trochanter-trochanter distance; (3) centrocalcar distance; (4) lesser trochanterarticular distance; (5) femoral neck length; and (6) femoral neck width.

post-operative head-neck slip angles were measured on anteroposterior (AP) and lateral radiographs taken at a standard $100 \mathrm{~cm}$ beam distance. ${ }^{24}$ Any change of $5^{\circ}$ or more was considered significant. ${ }^{25}$ A negative value was considered a decrease and a positive value an increase in slip angle.

Epiphyseal-physeal growth was assessed by measurements of articulotrochanteric distance, trochantertrochanter distance, centre of lesser trochanter to articular surface distance, centrocalcar distance, neck length and neck width. Neck length was measured from the physis to the lateral femoral cortex of the trochanter on the central long axis of the femur, and width was measured from the central femoral neck axis to the physis (Fig. 1).

The time to closure of the proximal femoral epiphysis of the involved and uninvolved sides following surgery was assessed. The physis was considered closed when at least
$50 \%$ closure was seen on AP and lateral radiographs. ${ }^{25}$ Closure of the acetabular triradiate cartilage was also reviewed.

All measurements were independently determined by two observers (VG and FF) and inter-observer correlations evaluated by a paired $t$-test. Student's paired $t$-test was used to compare all measurements of normal and involved sides from the beginning of treatment to proximal femoral physeal closure. A p value of 0.05 was considered significant.

Clinical assessment of the hip was made using the modification by Zahrawi et $\mathrm{al}^{15}$ of the classification of Heyman and Herndon ${ }^{26}$ in which an excellent result has a normal range of hip movement, no limp, no pain and leg shortening of $<5 \mathrm{~mm}$. A good result has slight limitation of internal rotation, occasional pain and leg shortening of $<5 \mathrm{~mm}$. A fair result has persistent mild pain, loss of internal rotation and abduction and leg shortening of $>1 \mathrm{~cm}$. A poor result does not meet any of the above criteria.

Operative technique. Surgery was carried out under fluoroscopic control. Spontaneous reduction occurred in the unstable slips. ${ }^{18,27}$ A modified cannulated screw 90 to 120 $\mathrm{mm}$ long with a smooth $5 \mathrm{~mm}$ diameter shank and $9 \mathrm{~mm}$ screw head was used. The modified AO cannulated screw (HIT-MEDICA, Rimini, Italy) had a distal segment with the original six threads reduced to three which were $9 \mathrm{~mm}$ long and $6.4 \mathrm{~mm}$ in diameter. The screw was inserted over a guide wire after pre-drilling. The threaded portion of the screw was placed entirely within the epiphysis with the smooth shank through the physis, femoral neck and lateral femoral cortex. The screw head was allowed to remain 2 to $3 \mathrm{~cm}$ lateral to the lateral femoral cortex. This distance was based on the predicted growth of the proximal femur plus a few additional millimetres to facilitate removal over a guide wire if necessary. ${ }^{23}$ The position of the screw in the central quadrant of the femoral epiphysis was confirmed by multiple fluoroscopic views. The screw tip was positioned more than $2.5 \mathrm{~mm}$ from the epiphyseal subchondral bone. After insertion of the screw, the hip was taken through a full range of movement with multiple fluoroscopic views to check the final position.

Post-operatively, patients with a stable SCFE were allowed to weight-bear as tolerated. Those with an unstable

Table I. Details and growth prediction data for ten skeletally immature children with SCFE

\begin{tabular}{cllllll}
\hline Case & Gender & $\begin{array}{l}\text { Age } \\
\text { (yrs) }\end{array}$ & $\begin{array}{l}\text { Bone }_{\text {(yrs) }} \\
\text { (yge }\end{array}$ & $\begin{array}{l}\text { Growth prediction } \\
\text { of leg } \mathbf{( c m )}\end{array}$ & Type of slip & $\begin{array}{l}\text { Clinical follow-up } \\
\text { (mths) }\end{array}$ \\
\hline 1 & M & 11.5 & 12 & 9 & Stable & 76 \\
2 & M & 11.9 & 12.6 & 9 & Unstable & 46 \\
3 & M & 10.6 & 11 & 12.5 & Unstable & 54 \\
4 & F & 10.6 & 10 & 12 & Stable & 42 \\
5 & M & 11.8 & 12.6 & 9 & Stable & 42 \\
6 & M & 11 & 12 & 9 & Stable & 36 \\
7 & M & 12 & 12 & 8.5 & Stable & 36 \\
8 & M & 11 & 12 & 8 & Unstable & 39 \\
9 & M & 12 & 12.3 & 9 & Stable & 36 \\
10 & M & 12.6 & 12 & 8.5 & Unstable & 36 \\
\hline
\end{tabular}


Table II. The times to proximal femoral physeal closure for both the pathologically involved hip with SCFE treated by screw fixation and the uninvolved contralateral hip

\begin{tabular}{lll}
\hline & \multicolumn{2}{l}{ Physis survival (mths) } \\
\cline { 2 - 3 } Case & Pathological side & Contralateral side \\
\hline 1 & 30 & 30 \\
2 & 40 & 40 \\
3 & 48 & 54 \\
4 & 39 & 42 \\
5 & 30 & 30 \\
6 & 30 & 33 \\
7 & 36 & 36 \\
8 & 33 & 39 \\
9 & 36 & 36 \\
10 & 30 & 33 \\
\hline
\end{tabular}

SCFE used crutches with partial weight-bearing for four weeks.

\section{Results}

Ten patients, nine boys and one girl, with a mean age of 11.5 years (10.6 to 12.6 ) and a unilateral SCFE, were reviewed (Table I). There were six stable and four unstable. All were Tanner stage I. ${ }^{21}$ The mean bone age was 11.8 years (10 to 12.6), and the mean follow-up was 44.3 months (36 to 76 ).

Mean time to proximal femoral physeal closure $(50 \%$ on $\mathrm{AP}$ and lateral radiographs) was 35.2 months on the involved side and 37.3 months on the uninvolved side $(\mathrm{p}=$ 0.02) (Table II). Complete closure of the tri-radiate cartilage occurred approximately 12 months prior to proximal femoral physeal closure.

No SCFE was noted on the contralateral side in this group. Three patients in the original cohort were excluded from the study when they developed SCFE of the contralateral hip which made comparative measurements impossible. There was no evidence of avascular necrosis or chondrolysis. The time from presentation to surgery for those with an unstable slip was within 12 hours in two children who underwent spontaneous reduction for slips of $>30^{\circ}$ (cases 8,10 ). In two other children with unstable slips (cases 2, 3) which were not repositioned, the slip was $<30^{\circ}$ and the time from presentation to surgery was 12 and 24 hours. Eight of ten patients showed a change of the angle of slip of $>5^{\circ}$ at follow-up, compared to their immediate postoperative values, indicating metaphyseal recovery and remodelling (Table III). ${ }^{17,25}$

Table III. Radiological measurements of slip pre-operatively, post-operatively and at follow-up, and the clinical grading of hip outcome following the modified criteria of Hayman and Herndon ${ }^{26}$

\begin{tabular}{|c|c|c|c|c|c|c|c|c|}
\hline \multirow[b]{2}{*}{ Case } & \multicolumn{2}{|c|}{ Pre-operative slip ( ${ }^{\circ}$ ) } & \multirow[b]{2}{*}{$\begin{array}{l}\text { Type of } \\
\text { treatment* }\end{array}$} & \multicolumn{2}{|c|}{ Post-operative slip ( ${ }^{\circ}$ ) } & \multicolumn{2}{|c|}{ Slip at follow-up ( $\left.{ }^{\circ}\right)$} & \multirow[b]{2}{*}{ Hip function } \\
\hline & AP view & $\begin{array}{l}\text { Lateral } \\
\text { view }\end{array}$ & & AP view & $\begin{array}{l}\text { Lateral } \\
\text { view }\end{array}$ & AP view & $\begin{array}{l}\text { Lateral } \\
\text { view }\end{array}$ & \\
\hline 1 & 0 & 20 & SSF & 0 & 20 & 0 & 10 & Excellent \\
\hline 2 & 10 & 24 & SSF & 10 & 24 & 0 & 0 & Excellent \\
\hline 3 & 0 & 20 & SSF & 0 & 20 & 0 & 0 & Excellent \\
\hline 4 & 8 & 28 & SSF & 8 & 28 & 0 & 14 & Excellent \\
\hline 5 & 0 & 35 & SSF & 0 & 35 & 0 & 20 & Excellent \\
\hline 6 & 10 & 25 & SSF & 10 & 25 & 5 & 20 & Excellent \\
\hline 7 & 0 & 40 & SSF & 0 & 40 & 0 & 30 & Excellent \\
\hline 8 & 40 & 0 & Red and SSF & 0 & 0 & 0 & 0 & Excellent \\
\hline 9 & 0 & 40 & SSF & 0 & 40 & 0 & 30 & Excellent \\
\hline 10 & 40 & 60 & Red and SSF & 0 & 0 & 0 & 0 & Excellent \\
\hline
\end{tabular}

* SSF, single-screw fixation; red, spontaneous reduction

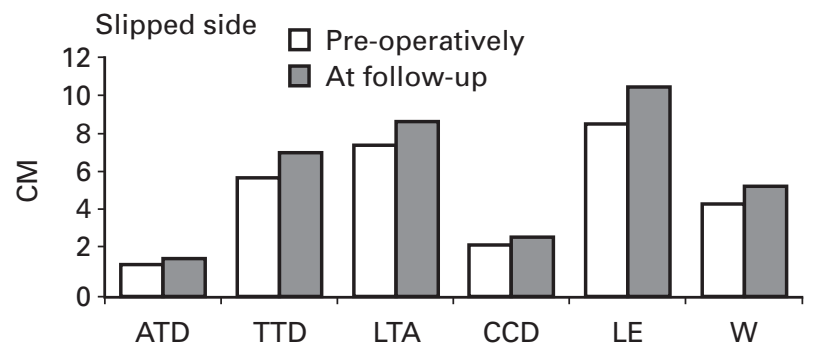

Fig. 2a

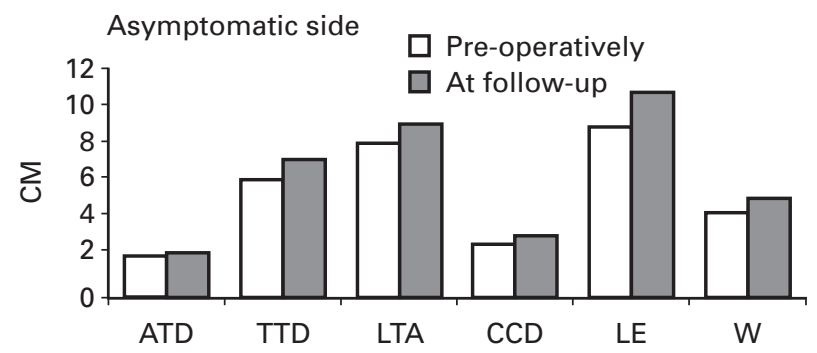

Fig. 2b

Radiological growth comparisons at the time of treatment and final follow-up after physeal closure a) for the slipped side and b) for the asymptomatic side. ATD, articulotrochanteric distance; TTD, trochanter-trochanter distance; LTA, centre of trochanter to articular surface distance; CCD, centrocalcar distance; LE, femoral neck length; W, femoral neck width. 


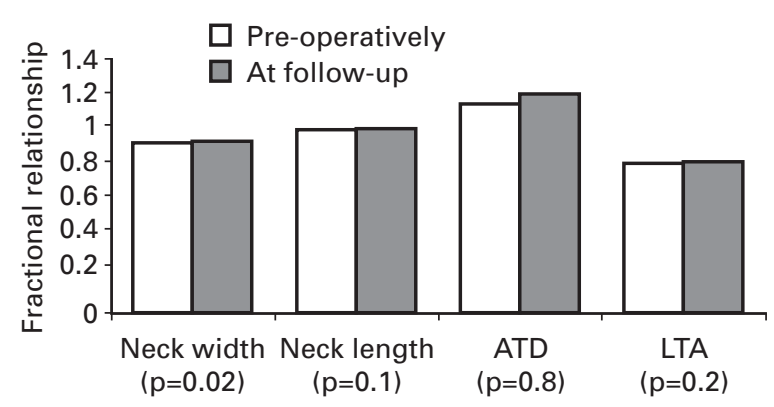

Fig. $3 a$

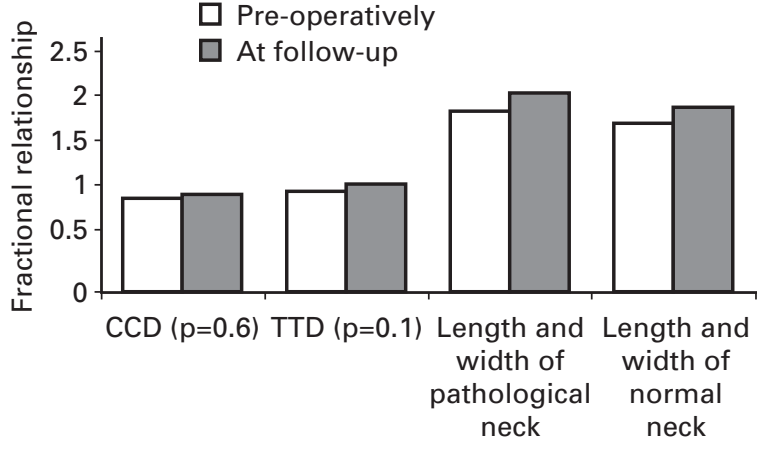

Fig. 3b

Radiological growth comparisons between the slipped and asymptomatic sides at the time of treatment and final follow-up after physeal closure. Figure $3 a$ - The relationship for the width of the neck, length of the neck, the articulo-trochanteric distance (ATD) and the centre of lesser trochanter (LTA). Figure 3b-The relationship for the trochanter-trochanter distance (TTD) and centrocalcar distance (CCD), as well as the relationship between the length and width of the normal neck and the length and width of the pathological neck.

As shown in Figure 2, at the onset of treatment there was a statistically significant difference between the normal and affected side relative to femoral neck length $(\mathrm{p}$ $=0.01)$, articulotrochanteric distance $(\mathrm{p}=0.005)$, centre of lesser trochanter to articular surface distance $(\mathrm{p}=$ $0.02)$, and centrocalcar distance $(\mathrm{p}=0.03)$. No significant difference could be detected in neck width $(\mathrm{p}=0.2)$ and trochanter-trochanter distance $(\mathrm{p}=0.2)$. At presentation, the side with the slip had a shorter 'neck' length, mainly due to the slip itself in measurement of articulotrochanteric distance and centre of lesser trochanter to articular surface distance. It was not due to changes in the measurement of either the centrocalcar distance or the length of the neck.

At final follow-up, both the affected and unaffected femoral necks had continued to grow (Fig. 3). The only statistically significant differences were detected in neck width $(\mathrm{p}$ $=0.005)$, neck length $(\mathrm{p}=0.07)$, articulotrochanteric distance $(\mathrm{p}=0.04)$ and centrocalcar distance $(\mathrm{p}=0.03)$. As shown in Figure 2, no significant difference was seen in centre of lesser trochanter to articular surface distance $(\mathrm{p}=$ $0.1)$ and trochanter-trochanter distance $(\mathrm{p}=0.9)$. The differential relationships between the normal and the affected side showed no statistically significant difference between measurements at the onset of treatment and at those at final follow-up (Fig. 3).

As growth of the femoral neck progressed, the screw advanced into the femoral neck from the lateral femoral cortex, closing the gap between the lateral femoral cortex and the screw head (Fig. 4).

The clinical results in all patients were rated as excellent and all resumed full activity within three to four months of surgery and have remained fully active (Table III).

\section{Discussion}

A single modified cannulated screw was used to treat unilateral SCFE in markedly skeletally immature patients and achieved epiphyseal stability. Premature proximal femoral physeal closure was prevented and the potential complications of avascular necrosis and chondrolysis avoided. The screw allowed continued growth of the femoral neck and epiphyseal/physeal complex and remodelling of the epiphysis and metaphysis. ${ }^{17}$

Other types of fixation which allow continued physeal growth have been proposed. ${ }^{12,13,28}$ In our series, we did not observe zones of radiolucency or sclerosis in the femoral neck in response to movement of the fixation device between the neck and epiphysis. ${ }^{13}$ We did not see a 'growing away' of the epiphysis from the fixation as reported by authors using other implants. ${ }^{11,29}$ None of our patients developed loosening of the screw at the lateral femoral cortex or symptomatic bursitis at the screw head. We feel that these complications were avoided by the progressive reduction of protrusion of the screw as growth occurs and the rounded screw head in contrast to the shape of the vonBar screw ${ }^{4}$ or Lars Ingvar Hansson hook pin. ${ }^{13}$

The radiological data showed that, in these younger patients, this single modified cannulated screw provided stability and allowed improvement of the pathological epiphyseal/physeal and metaphyseal morphology by remodelling ${ }^{17}$ due to continued physeal growth. ${ }^{16}$ By reviewing strictly unilaterally involved patients we were able to compare proximal femoral growth and development in the affected and unaffected side. At the time of surgery, radiological measurements demonstrated a statistically significant $(\mathrm{p}=0.01)$ delay in longitudinal femoral neck growth on the involved side. The degree of alteration of the endochondral ossification, that will still allow substantial growth and remodelling, is unknown. In our series, once the epiphysis was stabilised by screw fixation, the physis grew in a similar way to the opposite side. ${ }^{2}$ The physeal survival was longer (up to 48 months) in our immature patients than that reported in a more mature population $(9$ to 18 months). ${ }^{29}$ 


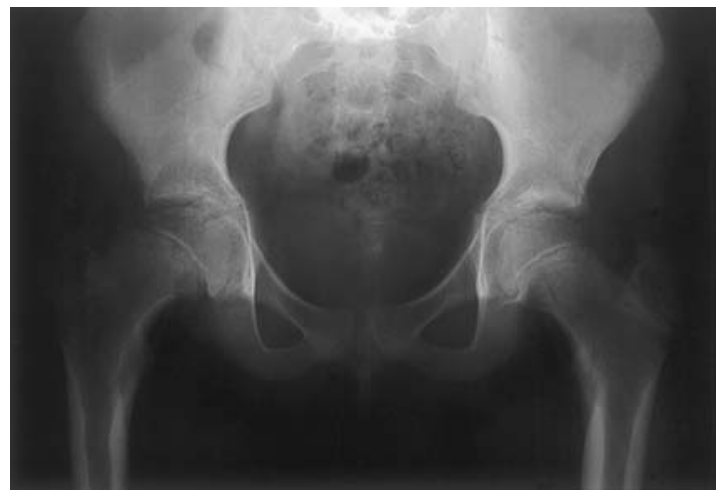

Fig. 4a

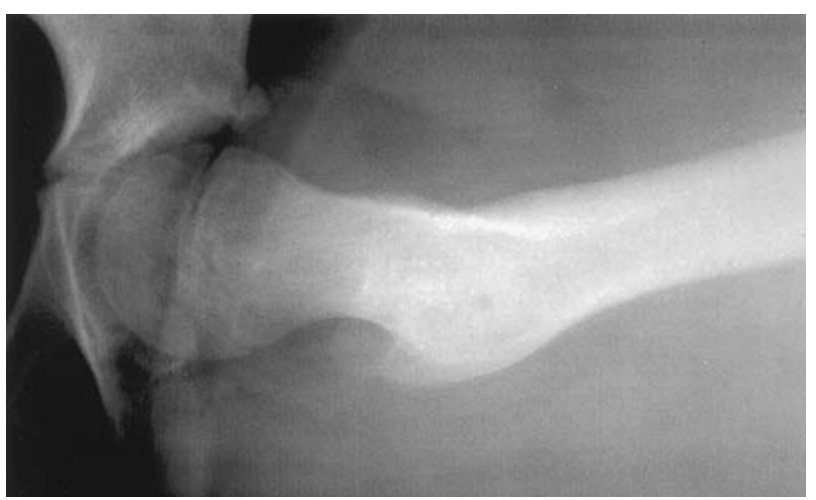

Fig. 4c

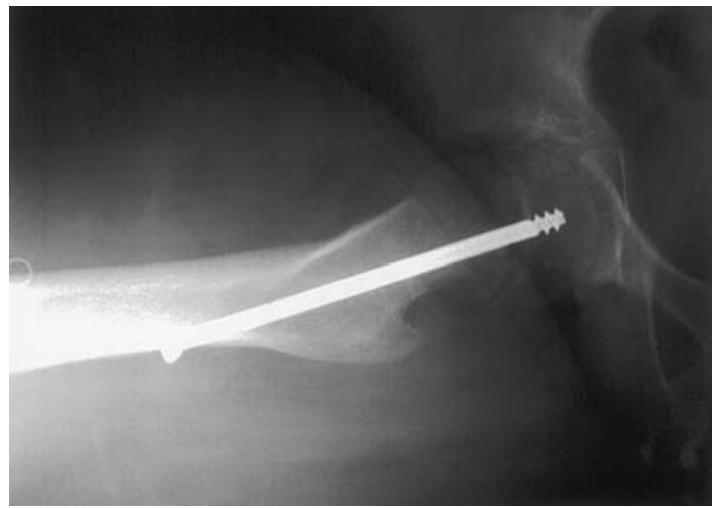

Fig. 4e

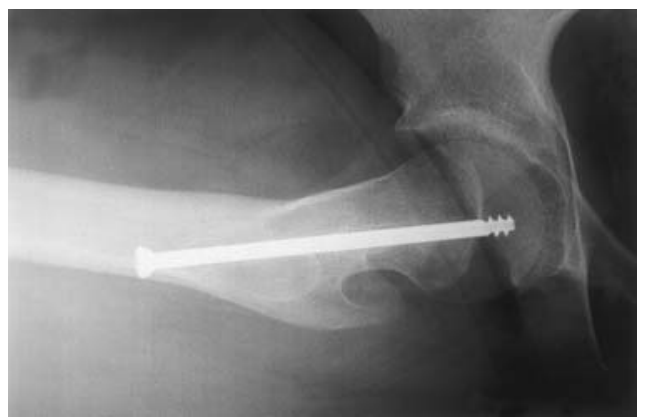

Fig. $4 \mathrm{~g}$

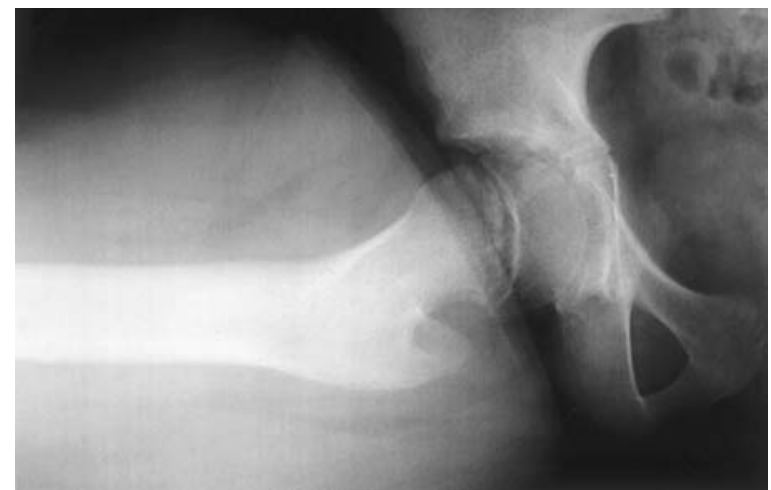

Fig. $4 b$

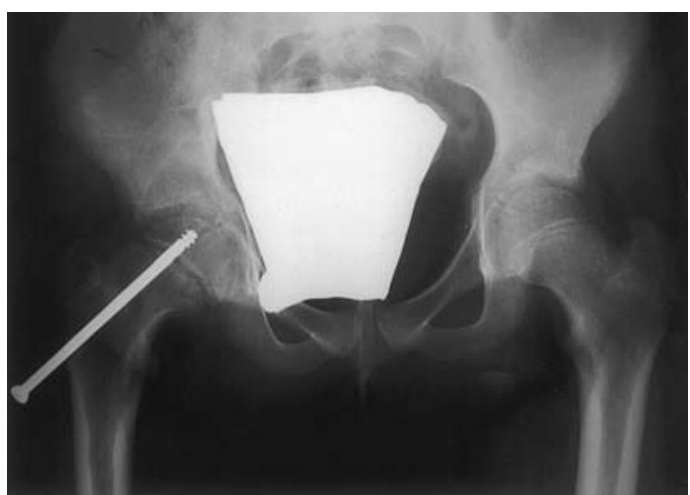

Fig. 4d

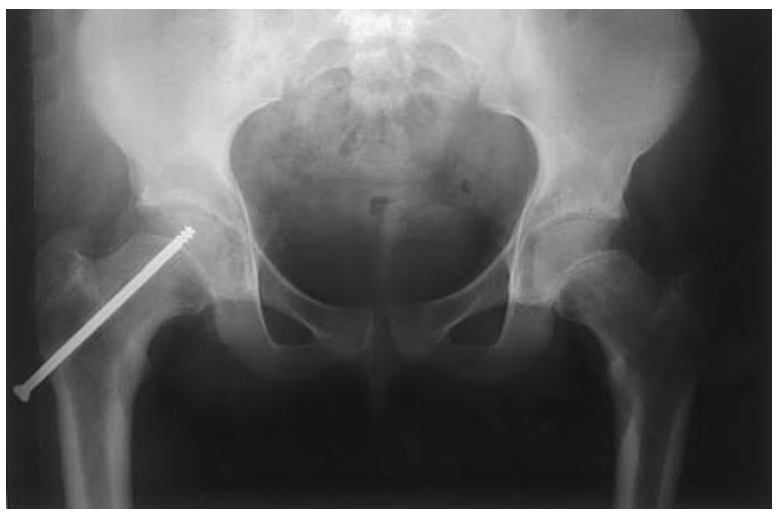

Fig. $4 f$

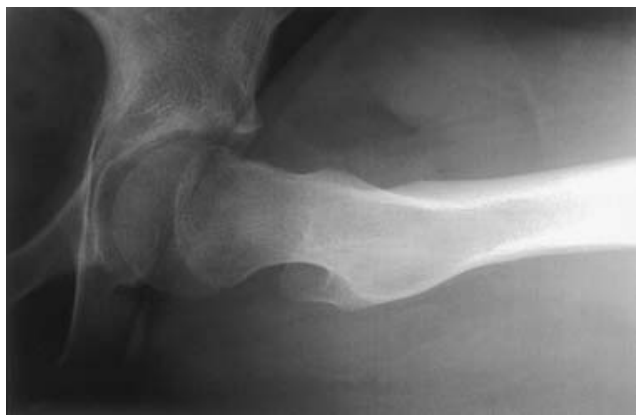

Fig. 4h

Radiographs of a ten-year-old girl (case 4), a) pre-operative AP view with $8^{\circ}$ of slip, b) pre-operative lateral view with a slip of $28^{\circ}$, c) lateral view of uninvolved side, d) post-operative AP view with $8^{\circ}$ of slip, e) post-operative lateral view $28^{\circ}$ of slip, f) $A P$ with $0^{\circ}$ of slip of the uninvolved side at follow-up, g) lateral view at follow-up of the involved side, $14^{\circ}$ of slip and h) lateral view at follow-up of the uninvolved side. At follow-up the involved physis closed at 39 months and the uninvolved at 42 months. Remodelling is demonstrated by resolution of the metaphyseal bump, decrease in the measurable SCFE. 
We feel that the change in the angle of slip with reference to the neck occurs from differential remodelling and growth of the neck (medial > lateral; posterior $>$ anterior) once stabilisation has occured. ${ }^{30}$ This process is not unlike that seen following distal radial physeal fractures and subsequent remodelling.

The biological mechanism by which physeal pathological changes in SCFE can be reversed after stabilisation of the epiphysis is not known at present.

No benefits in any form have been received or will be received from any commercial party related directly or indirectly to the subject of this article.

\section{References}

1. Carney BT, Weinstein SL, Noble J. Long-term follow-up of slipped capital femoral epiphysis. J Bone Joint Surg [Am] 1991;73-A:667-74.

2. Loder RT, Aronsson DD, Dobbs MB, Weinstein SL. Slipped capital femoral epiphysis. J Bone Joint Surg [Am]2000;82-A:1170-88.

3. Ward WT, Stefko J, Wood KB, Stanitski CL. Fixation with a single screw for slipped capital femoral epiphysis. J Bone Joint Surg [Am] 1992;74-A:799-809.

4. Jerre R, Karlsson J, Romanus B, Wallin J. Does a single device prevent further slipping of the epiphysis in children slipped capital femoral epiphysis. Arch Orthop Trauma Surg 1997;116:348-51.

5. Morrissy RT. In situ fixation of chronic slipped capital femoral epiphysis. Instructional Course Lectures: The American Accademy of Orthopaedic Surgeons, St Louis, C V Mosby, 1984;Vol 33:319-27.

6. Laplaza FJ, Burke SW. Epiphyseal growth after pinning of slipped capital femoral epiphysis. J Pediatr Orthop 1995;15:357-61.

7. Bennet GC, Koreska J, Rang M. Pin placement in slipped capital femoral epiphysis. J Pediatr Orthop 1984;4:574-8.

8. Brodetti A. The blood supply of the femoral neck and head in relation to the damaging effects of nails and screws. J Bone Joint Surg [Br] 1960;42-B:794-801.

9. Jones JR, Paterson DC, Hillier TM, Foster BK. Remodelling after pinning slipped capital femoral epiphysis. J Bone Joint Surg [Br] 1990;72-B:568-73.

10. O'Brien ET, Fahey JJ. Remodelling of the femoral neck after in situ pinning for slipped capital femoral epiphysis. J Bone Joint Surg [Am] 1977;59-A:62-8.

11. Segal LS, Davidson RS, Robertson WW, Drummond DS. Growth disturbances of the proximal femur after pinning of juvenile slipped capital femoral epiphysis. J Pediatr Orthop 1991;11:631-7.
12. Hagglund G, Bylander B, Hansson LL, Selvik G. Bone growth after fixing slipped femoral epiphyses: brief report. J Bone Joint Surg [Br] 1988;70-B:845-6.

13. Hansson LI. Osteosynthesis with the hook-pin in slipped capital femoral epiphysis. Acta Orthop Scand 1982;53:87-96.

14. Ordeberg G, Hagglund G, Hansson LL, Sandstrom S. Articulotrochanteric distance in slipped capital femoral epiphysis. Arch Orthop Trauma Surg 1990;109:191-3.

15. Zahrawi F, Stephens T, Spencer G, Clough J. Comparative study of pinning in situ and open epiphysiodesis in 105 patients with slipped femoral capital epiphysis. Clin Orthop 1983;177:160-8.

16. Kallio PE, Foster BK, LeQuesne GW, Paterson DC. Remodelling in slipped capital femoral epiphysis: sonographic assessment after pinning. J Pediatr Orthop 1992;12: 438-43

17. Clarke NMP, Harrison MHM. Slipped upper femoral epiphysis: a potential for spontaneous recovery. J Bone Joint Surg [Br] 1986;68-B:541-5.

18. Goodman WW, Johnson JT, Robertson WW Jr. Single screw fixation for acute and acute-on-chronic slipped capital femoral epiphysis. Clin Orthop 1996;322:86-90.

19. Boyer DW, Michelson MR, Ponsetti IV. Slipped capital femoral epiphysis: longterm follow-up study of one hundred and twenty-one patients. J Bone Joint Surg [Am] 1981;63-A:85-95.

20. Acheson RM. The Oxford method of assessing skeletal maturity. Clin Orthop 1957; 10:19-39.

21. Tanner JM. Foetus into man. Cambridge, Horwood University press, 1990.

22. Anderson M, Green WT, Messmer MB. Growth and predictions of growth in the lower extremities. J Bone Joint Surg [Am] 1963;54-A:1-14.

23. Dimeglio A. La croissance in orthopèdie. Encycl Med Chir Paris, Appareil locomoteur, 3-14009 1984;A-10,1-8

24. Guzzanti V, Falciglia F. Slipped capital femoral epiphysis: comparison of a roentgenographic method and computed tomography in determining slip severity. J Pediatr Orthop 1991;11:6-12

25. Rao SB, Crawford AH, Burger RR, Roy DR. Open bone peg epiphysiodesis for slipped capital femoral epiphysis. J Pediatr Orthop 1996;16:37-48.

26. Heyman $\mathbf{C H}$, Herndon $\mathbf{C H}$. Epiphysiodesis for early slipping of the femoral epiphysis. J Bone Joint Surg [Am] 1954;36-A:539-55.

27. Jerre R, Hansson G, Wallin J, Karlsson J. Long term results after realignment operations for slipped upper femoral epiphysis. J Bone Joint Surg [Br] 1996;78-A: 745-50

28. Hartjen CA, Koman LA. Treatment of slipped capital femoral epiphysis resulting from juvenile renal osteodystrophy. J Pediatr Orthop 1990;10:551-4

29. Melby A, Hoyt WA Jr, Weiner DS. Treatment of chronic slipped capital femoral epiphysis by bone-grafted epiphyseodesis. J Bone Joint Surg [Am]1980;62-A:119-25.

30. Weinstein SL. Long-term follow-up of pediatric orthopaedic conditions: natural history and outcomes of treatment. J Bone Joint Surg [Am]2000;82-A:980-90. 